\title{
Qualidade do melão tipo Galia durante o armazenamento refrigerado.
}

\author{
Josivan B. Menezes ${ }^{1}$; Adimilson B. Chitarra ${ }^{2}$ M $^{\mathrm{a}}$. Isabel F.Chitarra ${ }^{2}$; Urquisa O. Bicalho. ${ }^{2}$ \\ ${ }^{1}$ ESAM - Núcleo de Estudos em Pós-colheita - QTC, C. Postal 137, 59625-900 Mossoró-RN; ${ }^{2}$ UFLA - DCA C. Postal 037, 37200 - \\ 000 Lavras - MG.
}

\section{RESUMO}

Com o propósito de avaliar a qualidade pós-colheita do melão tipo Galia, híbrido Nun 1380 , armazenado sob refrigeração $\left(7 \pm 1^{\circ} \mathrm{C}\right.$, $\mathrm{UR}=88 \pm 3 \%$ ) instalou-se um experimento em Lavras-MG com frutos provenientes do Pólo Agrícola Mossoró-Assu-RN. Os frutos foram colhidos no estádio de maturação I, selecionados e tratados com prochloraz ( $300 \mathrm{ml} .1^{-1}$ do produto comercial), secos à temperatura ambiente, embalados e transportados para Lavras-MG, onde foram armazenados à temperatura de $7 \pm 1^{\circ} \mathrm{C}$ e UR de $88 \pm 3 \%$. Montou-se um experimento em delineamento inteiramente casualizado composto de oito tratamentos. Observou-se um aumento na perda de peso durante 35 dias de armazenamento e perda na firmeza da polpa. Entretanto, não houve associação entre amolecimento de frutos e aumento de pectina solúvel. Não observou-se efeito do período de armazenamento no $\mathrm{pH}$, concordante com a estabilização da acidez total titulável. Os teores de sólidos solúveis totais, açúcares solúveis totais e açúcares não-redutores diminuíram durante o armazenamento, entretanto, o teor de açúcares redutores mantevese constante. Houve redução nos teores de vitamina $\mathrm{C}$ total e clorofila total. A aparência interna limitou o tempo de vida útil pós-colheita do melão tipo Galia, híbrido Nun 1380 em 26 dias quando mantido sob refrigeração.

Palavras-chave: Cucumis melo L., pós-colheita, refrigeração.
ABSTRACT

Quality of 'Galia' type melon during refrigerated storage.

The purpose of this research was to examine the postharvest quality of 'Galia' melon, hybrid Nun 1380, at refrigerated storage ( $7 \pm 1^{\circ} \mathrm{C}$, RH $88 \pm 3 \%$ ). This study was carried out in Lavras-MG with fruits from Pólo Agrícola Mossoró-Assu-RN. Fruits were harvested at maturation stage II and selected for good external characteristics. Fruits were treated with prochloraz $\left(300 \mathrm{ml}^{-1} \mathrm{l}^{-1}\right)$ and dried at room temperature. After packing fruits were transported to Lavras-MG. The experiment was carried out in a complete randomized design with eight treatments (eight storage times: 0, 5, $10,15,20,25,30$ and 35 days). Reduction in fruit wheight and flesh firmness were observed during storage period. There was no association between softening of fruits and increasing of soluble pectin. The $\mathrm{pH}$ and titratable acidity did not change during storage. Soluble solids content, total sugars and non-reducing sugars decreased significantly $(\mathrm{p}<0,05)$ during storage, but reducing sugars content was not affected by the storage period. The contents of total vitamin $\mathrm{C}$ and total chlorophyll decreased during storage. The storage period of 'Galia' melon was reduced to 26 days. After this period the internal fruit appearance decresed $\left(25\right.$ days of storaging $-7 \pm 1^{\circ} \mathrm{C}$, RH $88 \pm 3 \%$ - plus one day prior to storage).

Keywords: Cucumis melo L., post-harvest, refrigeration.

\section{(Aceito para publicação em 20 de julho de 1998)}

$\mathrm{A}$ exportação de melão do Brasil expandiu-se rapidamente nos últimos anos, tendo nos países da Comunidade Econômica Européia, o seu principal mercado. Devido à grande distância deste mercado, o país só tem exportado melão com vida útil pós-colheita com capacidade para resistir ao transporte marítimo (onze dias, em média), como é o caso do melão amarelo (Cucumis melo L. var. inodorus ). A exportação de melões "nobres" é limitada em função de sua vida útil pós-colheita ser relativamente curta (uma a duas semanas), característica esta que exige o frete aéreo, reduzindo a margem de lucros em até $50 \%$, dependendo da época do ano .

Sob as técnicas normais de manuseio comercial de frutos, a perda de qualidade dos melões "nobres" ocorre normalmente dentro de apenas duas semanas (Ryall \& Lipton, 1972). Entretanto, os melões inodorus apresentam vida de armazenamento média de três a quatro semanas, podendo estender-se até cinco ou seis semanas, dependendo da cultivar. Os principais problemas encontrados no prolongamento da vida útil póscolheita dos melões nobres são a rápida taxa de respiração e a senescência dos frutos quando mantidos a temperaturas acima de $5^{\circ} \mathrm{C}$ e a suscetibilidade a injúrias pelo frio abaixo de $5^{\circ} \mathrm{C}$ (Edwards \& Blennerhassett, 1994).

O melão Galia é o principal tipo cultivado em Israel tanto para a comercialização no mercado externo quanto para o interno (Aharoni et al., 1990). Na Espanha, este tipo de melão representa $15 \%$ do volume de produção e $31 \%$ das exportações (Artés et al., 1993). Em ambos, os principais compradores são os países da Comunidade Econômica Européia (Milla, 1995).
No Brasil, o melão tipo Galia foi introduzido há cerca de três anos com o objetivo de suprir o mercado europeu, na entressafra dos concorrentes. Este tipo de melão é bastante apreciado pelo seu excelente sabor e aroma.

Este trabalho teve como objetivo avaliar a qualidade pós-colheita e o potencial de conservação do melão tipo Galia, híbrido Nun 1380 durante o armazenamento refrigerado.

\section{MATERIAL E MÉTODOS}

O plantio foi instalado em área do Pólo Agrícola Mossoró-Assu-RN e conduzido sob fertirrigação. Os tratos culturais e os procedimentos de colheita foram idênticos àqueles utilizados para o plantio comercial de melão na região. No período de condução da cultura, registrou-se precipitação pluviométrica de $109 \mathrm{~mm}$. 
Os frutos foram colhidos no estádio de maturação II (frutos verdes com início de descoloração e pedúnculo totalmente preso), 69 dias após o plantio. Imediatamente após a colheita, os frutos apresentando boas características externas foram tratados com prochloraz ( $300 \mathrm{ml}$ do produto comercial por litro, por três minutos) embalados em caixa de papelão. O transporte para LavrasMG foi realizado em $24 \mathrm{~h}$ à temperatura ambiente. $\mathrm{O}$ armazenamento dos frutos foi feito em câmara com circulação de ar a $7 \pm 1^{\circ} \mathrm{C}$ e UR $88 \pm 3 \%$.

$\mathrm{O}$ experimento foi conduzido em delineamento inteiramente casualizado, com oito tratamentos (tempos de armazenamento: 0, 5, 10, 15, 20, 25, 30 e 35 dias), e oito repetições. Devido à homogeneidade do material experimental, utilizou-se um fruto por parcela, totalizando 64 frutos.

Preparo das amostras: Separaram-se quatro fatias eqüidistantes $(2 \mathrm{~cm}$ de largura) das quais extraiu-se a polpa comestível. Após homogeneização em liqüidificador, uma porção da polpa foi filtrada e imediatamente utilizada para análises de $\mathrm{pH}$, acidez total titulável e sólidos solúveis e o restante para o doseamento de vitamina $C$ total e açúcares. A outra parte da polpa foi cortada em cubos, congelada em nitrogênio líquido, embalada em sacos transparentes de polietileno de baixa densidade $\left(27 \mathrm{~cm}^{\prime} 31 \mathrm{~cm}\right)$ com fecho hermético e mantida à $-18^{\circ} \mathrm{C}$ para utilização em análises posteriores.

A casca dos frutos foi congelada em $\mathrm{N}_{2}$ líquido e mantida à $-18^{\circ} \mathrm{C}$ para determinação do teor de clorofila total.

Aparência externa, aparência interna e injúria pelo frio: Os frutos foram avaliados através de escala de notas considerando a presença de defeitos na aparência externa: depressões, murcha ou ataque fúngico e injúrias pelo frio como manchas escuras na superfície do fruto e na aparência interna: colapso, sementes soltas e líquido na cavidade das sementes.

A escala subjetiva correspondeu às notas de 0 a 4 de acordo com a severidade dos defeitos, onde: $0=$ ausência de defeitos; $1=$ defeitos leves $(1-10 \%$ do fruto afetado); 2 = defeitos moderados $(11-30 \%) ; 3=$ defeitos severos (31$50 \%) ; 4=$ defeitos extremamente seve- ros (acima de 50\%). Considerou-se como fruto inadequado à comercialização aquele cuja nota foi igual ou superior a 3 para quaisquer avaliações.

Perda de peso: Foi determinada em percentagem considerando-se a diferença entre o peso inicial do fruto e aquele obtido a cada intervalo de tempo de amostragem. Como a perda de peso pelos frutos, durante o armazenamento, é atribuída principalmente à perda de umidade (Kader, 1992), neste experimento assumiu-se como sendo predominantemente perda de umidade.

Firmeza da polpa: Foi medida como a resistência à penetração utilizando-se penetrômetro (Magness-Taylor modelo $30 \mathrm{~A}$; valor máximo de leitura $30 \mathrm{lb}$ ) com plunger de ponta cônica (diâmetro, $0,83 \mathrm{~cm}$ e comprimento, $0,67 \mathrm{~cm}$ ). Foram feitas três determinações na região equatorial da superfície de cada fruto desprovido da casca, conforme McCollum et al. (1989).

Pectina total e solúvel: A polpa mantida sob $\mathrm{N}_{2}$ líquido foi desintegrada em homogeneizador de tecidos (Tissumizer - Tekmar company, tipo SDT 1880) e as frações pectina total e solúvel foram extraídas pelo método de McCready \& McCoomb (1952) a partir de 5 e $25 \mathrm{~g}$ de polpa homogeneizada, respectivamente. Para a hidrólise enzimática de pectina total utilizou-se pectinase (EC.3.2.1.15) de origem fúngica-Aspergillus niger, 1,0U/mg (Merck). Para a determinação da pectina total e da solúvel utilizou-se, após a extração da pectina, diluições 1:20 e 1:4 $\mathrm{v}: \mathrm{v}$, em água, respectivamente, e uma alíquota de 0,2 mo do extrato foi utilizada para comparação com as leituras obtidas pela curva padrão. Para evitar a interferência de açúcares (glicose, frutose, sacarose e celulose) (Kintner \& Van Buren, 1982) durante a determinação da fração pectina solúvel em água, a polpa foi mantida sob agitação em álcool etílico $95 \%$ (1:5 v:v) por 1hora antes da filtração.

A análise foi feita por colorimetria através da reação de condensação do mfenilfenol (m-hidroxibifenil - Eastman Kodak Company ou Sigma Company), segundo técnica adaptada de Blumenkrantz \& Asboe-Hansen (1973).
Observou-se a perda de coloração pelo cromóforo a partir da superfície do extrato em cerca de 30 minutos. Para evitar a instabilidade da reação e, conseqüentemente, a obtenção de resultados inconsistentes, as leituras foram feitas em ambiente com temperatura média de $25^{\circ} \mathrm{C}$ e umidade relativa inferior a $60 \%$. entre 15 e 30 minutos após o início de repouso do sistema.

A leitura foi monitorada em espectrofotômetro (modelo DU 640 B Beckman Instruments Inc. USA) a $520 \mathrm{~nm}$, operando com o sistema "Power Up Diagnostics Window". O aparelho foi calibrado para fornecer leituras médias de dez repetições a intervalos de 0,5 segundo. Os resultados foram expressos em mg de ácido urônico por $100 \mathrm{~g}$ de polpa.

Acidez total titulável, $\mathrm{pH}$ e sólidos solúveis: A partir do suco extraído da polpa fresca, registrou-se o $\mathrm{pH}$ em medidor de $\mathrm{pH}$ digital e a acidez total titulável através da titulação do suco (diluição 1:5) com $\mathrm{NaOH} 0,1 \mathrm{~N}$ e expressa como mg de ácido cítrico por $100 \mathrm{ml}$ de suco, conforme Artés et al.(1993).

Determinou-se o conteúdo de sólidos solúveis totais por leitura em refratômetro digital (modelo PR - 100, Palette; Atago Co., LTD., Japão) com compensação automática de temperatura. Os sólidos solúveis foram registrados com precisão de 0,1 a $25^{\circ} \mathrm{C}$ (Kramer, 1973).

Açúcares: As análises de açúcares foram feitas $24 \mathrm{~h}$ a partir da extração do suco, mantido em freezer. Os açúcares redutores e não-redutores foram analisados pelo método de Somoghy-Nelson (Southgate, 1991). Partiu-se, inicialmente, de uma alíquota de $3 \mathrm{ml}$ de suco, diluída para $100 \mathrm{ml}$ em água, usando-se $10 \mathrm{ml}$ da solução para hidrólise da sacarose e $3 \mathrm{ml}$ para desproteinização. $\mathrm{O}$ doseamento foi monitorado a partir de $0,2 \mathrm{ml}$ ou $0,3 \mathrm{ml}$ do extrato desproteinizado no caso dos açúcares redutores, e $1 \mathrm{ml}$ da solução após hidrólise da sacarose desproteinizada. Os resultados foram expressos em $\mathrm{g}$ de glicose por $100 \mathrm{ml}$ de suco.

Vitamina C total: Em parte do suco obtido da polpa fresca acrescentou-se ácido oxálico $(80 \mathrm{ml})$ e kiesselgur (seguido de filtração) e manteve-se a $-18^{\circ} \mathrm{C}$ para a avaliação do teor de vitamina $\mathrm{C}$, 
dentro de no máximo $24 \mathrm{~h}$. Em $20 \mathrm{ml}$ do extrato (suco diluído com ácido oxálico após clarificação), adicionou-se $80 \mathrm{ml} \mathrm{de}$ ácido oxálico $(0,5 \%)$ e para o doseamento, utilizou-se $1 \mathrm{ml}$ do filtrado para $3 \mathrm{ml}$ da solução de ácido oxálico $0,5 \%$. O ácido ascórbico (após oxidação à ácido dehidroascórbico) foi doseado pelo método colorimétrico com o 2,4-dinitrofenilhidrazina, segundo Strohecker \& Henning (1967). Os resultados foram expressos em $\mathrm{mg}$ por $100 \mathrm{ml}$ de suco.

Clorofila total: Foi determinada a partir da casca, previamente congelada em nitrogênio líquido, (espessura de aproximadamente $1 \mathrm{~mm}$ ). Utilizou-se para desintegração homogeneizador de tecidos, conforme metodologia desenvolvida por Bruinsma (1963), $1 \mathrm{~g}$ do material para $10 \mathrm{ml}$ de água destilada. Ao volume do extrato, após a homogeneização, adicionou-se acetona p.a. até sua completa descoloração. Em seguida, o extrato foi filtrado resultando em um volume final de $50 \mathrm{ml}$. A leitura da absorbância foi efetuada a $652 \mathrm{~nm}$. Os níveis de clorofila total foram determinados em $\mathrm{mg} / 100 \mathrm{~g}$ de casca, segundo a equação adotada por Engel \& Poggiani (1991):

$$
\begin{gathered}
\text { clorofila total }= \\
{\left[\left(A_{652}{ }^{\prime} 1000 ' v / 1000 w\right) / 34,5\right] ' 100}
\end{gathered}
$$

onde: $v=$ volume final do extrato clorofila-acetona; $\mathrm{w}=$ peso da casca em $\mathrm{g}$; $\mathrm{A}_{625}=$ leitura da absorbância a $652 \mathrm{~nm}$.

Análise estatística: As análises de variância foram efetuadas através do software SPSSPC (Norusis, 1990). Os critérios para a escolha da curva mais adequada foram: (1) o valor de $\mathrm{r}^{2}$ ajustado; (2) a significância estatística - F do $\mathrm{r}^{2}$; e (3) a significância dos parâmetros da equação testados pelo teste $t$. As regressões foram efetuadas através do programa Table Curve (Jandel Scientific, 1991).

\section{RESULTADOS E DISCUSSÃO}

As principais características que conferiram perda de qualidade externa dos frutos foram o murchamento e o surgimento de manchas escuras devido à senescência, acompanhadas de depressões superficiais, mais aparentes após

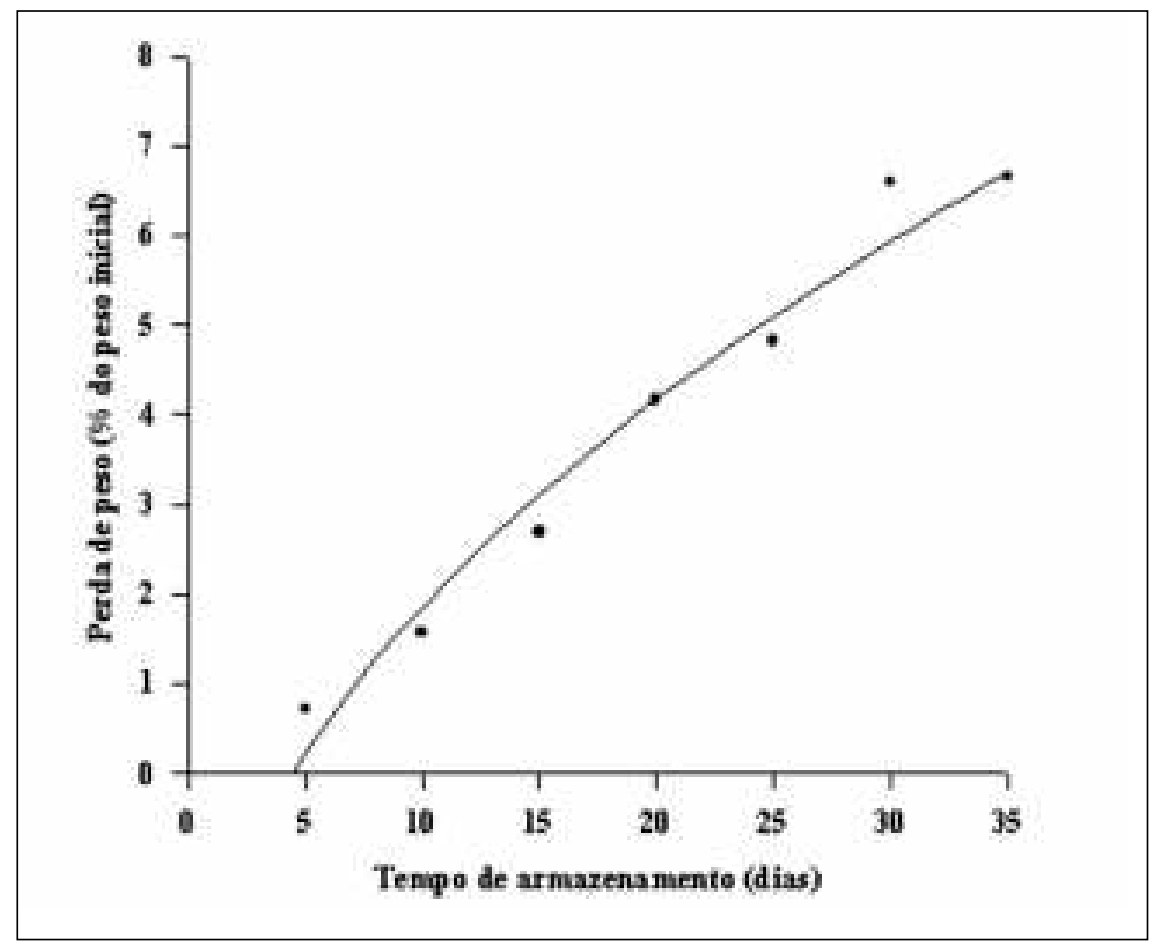

Figura 1. Perda de peso (\% em relação ao peso inicial) de melão tipo Galia, híbrido Nun 1380 , armazenado durante 35 dias sob temperatura de $7^{\circ} \mathrm{C} \pm 1^{\circ} \mathrm{C}$ e umidade relativa de $88 \% \pm 3 \%$. UFLA, Lavras-MG, 1996 .

35 dias de armazenamento. Miccolis \& Salteveit (1995) também verificaram aumento progressivo de manchas superficiais em frutos de melão armazenados a $7^{\circ} \mathrm{C}$ e umidade relativa próxima a $90 \%$. No presente trabalho, os frutos apresentaram pouca degradação interna (colapso interno, sementes soltas e líquido na cavidade) até os 26 dias pós-colheita (um dia de transporte em condições ambiente +25 dias em ambiente refrigerado). Considerando-se que os frutos com nota 33 eram inadequados ao consumo, conclui-se que a vida útil póscolheita do melão tipo Galia, híbrido Nun 1380, limita-se a 26 dias sob refrigeração $\left(7 \pm 1^{\circ} \mathrm{C}\right.$ e UR $88 \pm 3 \%$.). Estes dados são extremamente úteis na estimativa do limite de tempo de comercialização para o produto.

Apesar da alta suscetibilidade do melão tipo Galia às infecções fúngicas durante o armazenamento (Teitel et al., 1991), neste experimento não observaram-se contaminações com aparência macroscópica, nem na superfície do fruto, nem próximo ao pedúnculo, até 35 dias de armazenamento.

Houve efeito significativo $(\mathrm{p}<0,05)$ do período de armazenamento sobre a perda de peso dos frutos. Verificou-se aumento regular na perda de peso (Figura 1). A perda de peso foi, em média, $6,60 \%$ e $6,65 \%$ aos 30 e 35 dias de armazenamento, respectivamente. A susceptibilidade dos melões reticulados ao murchamento também foi verificada por Lester \& Bruton (1986).

A firmeza da polpa decresceu com o período de armazenamento (Figura 2), entretanto, não houve associação entre o amolecimento do fruto e o aumento de pectina solúvel. Estes resultados indicam que a perda de firmeza do mesocarpo do melão tipo Galia, híbrido Nun 1380, durante o armazenamento não pode ser atribuída somente à despolimerização e solubilização de protopectina, como sugere Bleinroth (1994). O amolecimento também pode estar relacionado à perda de integridade de membranas das células mesocárpicas hipodermais (Lester \& Stein, 1993), atribuída à atividade da lipoxigenase (EC 1.13.11.12) que causa alterações nas membranas microssomais (Lester, 1990). Outros fatores que podem estar envolvidos no amolecimento do melão são rompimento das interações iônicas entre polímeros 


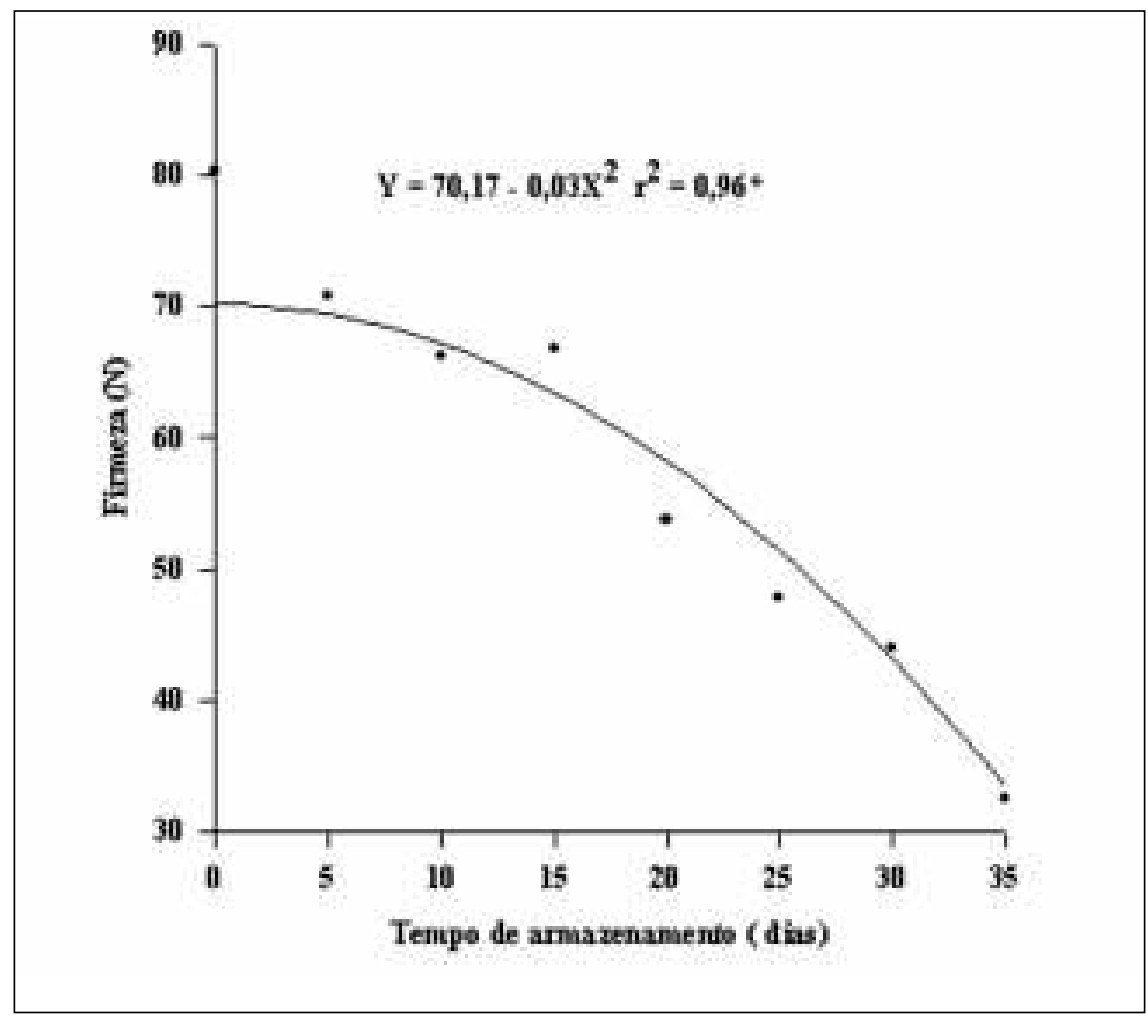

Figura 2. Firmeza da polpa (N) de melão tipo Galia, híbrido Nun 1380, armazenado durante 35 dias sob temperatura de $7^{\circ} \mathrm{C} \pm 1^{\circ} \mathrm{C}$ e umidade relativa de $88 \% \pm 3 \%$. UFLA, Lavras-MG, 1996 .

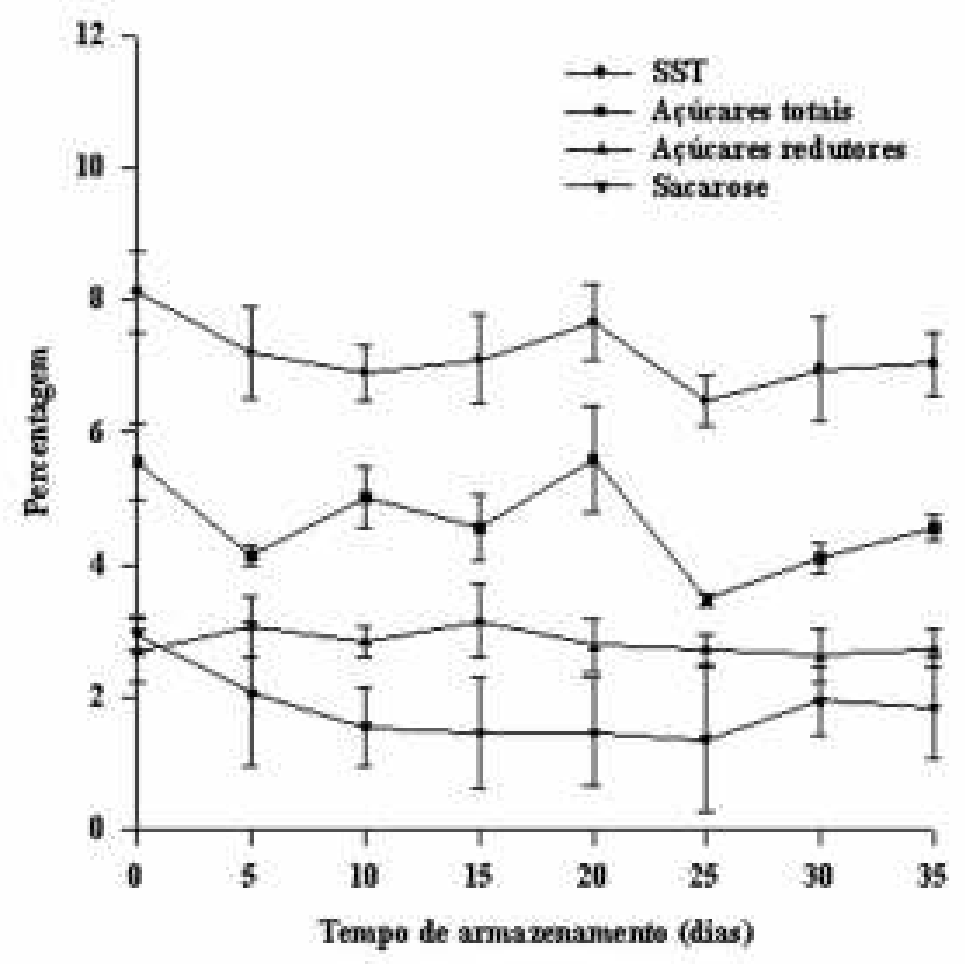

Figura 3. SS (\%), açúcares totais, açúcares redutores e sacarose (\% de glicose), de melão tipo Galia, híbrido Nun 1380 , armazenado durante 35 dias sob temperatura de $7^{\circ} \mathrm{C} \pm 1^{\circ} \mathrm{C}$ e umidade relativa de $88 \% \pm 3 \%$. UFLA, Lavras-MG, 1996 . da parede celular ou atuação de bgalactosidases (Ranwala et al., 1992).

Miccolis \& Salteveit (1995) observaram que após três semanas de armazenamento em ambiente refrigerado $\left(7,12\right.$ e $15^{\circ} \mathrm{C}$; UR @ 90\%) frutos das cvs. Honeydew, Amarelo, Juan Canary e Golden Casaba apresentaram redução na firmeza da polpa de 67,63 , 60 e $54 \%$, respectivamente. Entretanto, nas cvs. Paceco e Honey Loupe esta redução foi de apenas 40 e $32 \%$, nesta ordem.

Não houve efeito significativo do período de armazenamento sobre o $\mathrm{pH}$ e a acidez total titulável dos frutos. Em geral, este comportamento é observado quando os frutos são armazenados, independentemente da temperatura. A tendência na estabilidade destas variáveis durante o armazenamento mostra que ambas não são bons indicadores para a avaliação da qualidade dos frutos de melão após a colheita.

Os teores de sólidos solúveis e açúcares solúveis totais apresentaram pouca redução $(\mathrm{p}<0,05)$ durante o armazenamento (Figura 3). Em ambos, a redução mais pronunciada ocorreu durante os primeiros cinco dias de armazenamento. Isto pode ser atribuído ao consumo de açúcares via mecanismo respiratório. Ao contrário de frutos climatéricos como banana e maçã que armazenam apreciáveis quantidades de amido para conversão em açúcares durante o armazenamento (Brady \& Young, 1987), o tecido mesocárpico do melão não contém reserva de amido por ocasião da colheita.

Entre os principais açúcares solúveis encontrados no melão (sacarose, glicose e frutose), apenas o teor de açúcares nãoredutores, calculado como percentagem de sacarose apresentou redução significativa da ordem de 38\% (Figura 3). Como houve consumo de açúcares durante o armazenamento, é normal que aqueles redutores formados durante a conversão da sacarose tenham sido prontamente utilizados. Isto justifica o comportamento relativamente constante do teor de açúcares redutores durante o período experimental.

Em melão, a degradação da sacarose é atribuída à atividade da invertase (bfrutofuranosidase, EC 3.2.1.26) produ- 
zindo glicose e frutose (McCollum et al., 1988). A redução de sacarose tem sido relacionada também ao aumento da atividade da sacarose sintase em alguns regimes de armazenamento. A atividade da sacarose fosfato sintase, geralmente, declina durante o armazenamento. $\mathrm{O}$ conteúdo de sacarose foi inversamente proporcional à atividade da invertase em vários frutos (Hawker 1969; Manning \& Maw 1975; Walker \& Hawker, 1976; Yamaki \& Ishikawa, 1986). Em geral, as mudanças nos níveis de sacarose de melão após a colheita são atribuídas a um equilíbrio estabelecido entre as atividades das enzimas sacarose fosfato sintase, invertase ácida e sacarose sintase e não da atividade de uma dessas enzimas em particular (Knee et al., 1991).

$\mathrm{O}$ conteúdo de vitamina $\mathrm{C}$ total (ácido ascórbico + ácido dehidroascórbico) foi afetado significativamente pelo tempo de avaliação, havendo oxidação destes componentes durante o período experimental. A redução foi de $35 \%$ até 25 dias de armazenamento. Evensen (1983), também observou decréscimo do conteúdo de ácido ascórbico durante o armazenamento de cultivares de melão do tipo cantaloupe.

Das quatro enzimas responsáveis pela destruição oxidativa da vitamina $\mathrm{C}$ em frutos - ácido ascórbico oxidase, fenolase, citocromo $\mathrm{C}$ oxidase $\mathrm{e}$ peroxidase - (Aycward \& Haisman, 1969), apenas com ácido ascórbico oxidase reage diretamente com o substrato (Mapson, 1970) e esta parece ser a responsável pela degradação de vitamina $\mathrm{C}$ total no melão. Isto pode ser confirmado a partir do trabalho de Saari et al. (1995) que registraram que a ácido ascórbico oxidase (AAO) apresenta alta atividade no melão (cvs. Prince, Andes, Kinsho e Papaya) quando comparada com aquela apresentada por frutos como laranja e maçã.

Houve efeito significativo $(\mathrm{p}<0,5)$ do período de armazenamento do fruto no teor de clorofila total. No início do armazenamento o fruto apresentou teor de clorofila total de $47,92 \mathrm{mg} / 100 \mathrm{~g}$ de casca fresca e no final, de $20,83 \mathrm{mg} / 100 \mathrm{~g}$, equivalente a uma redução de $56,3 \%$ (Figura 4). Apesar deste declínio no teor de clorofila total o fruto ainda apresentou superfície esverdeada aos 35 dias de

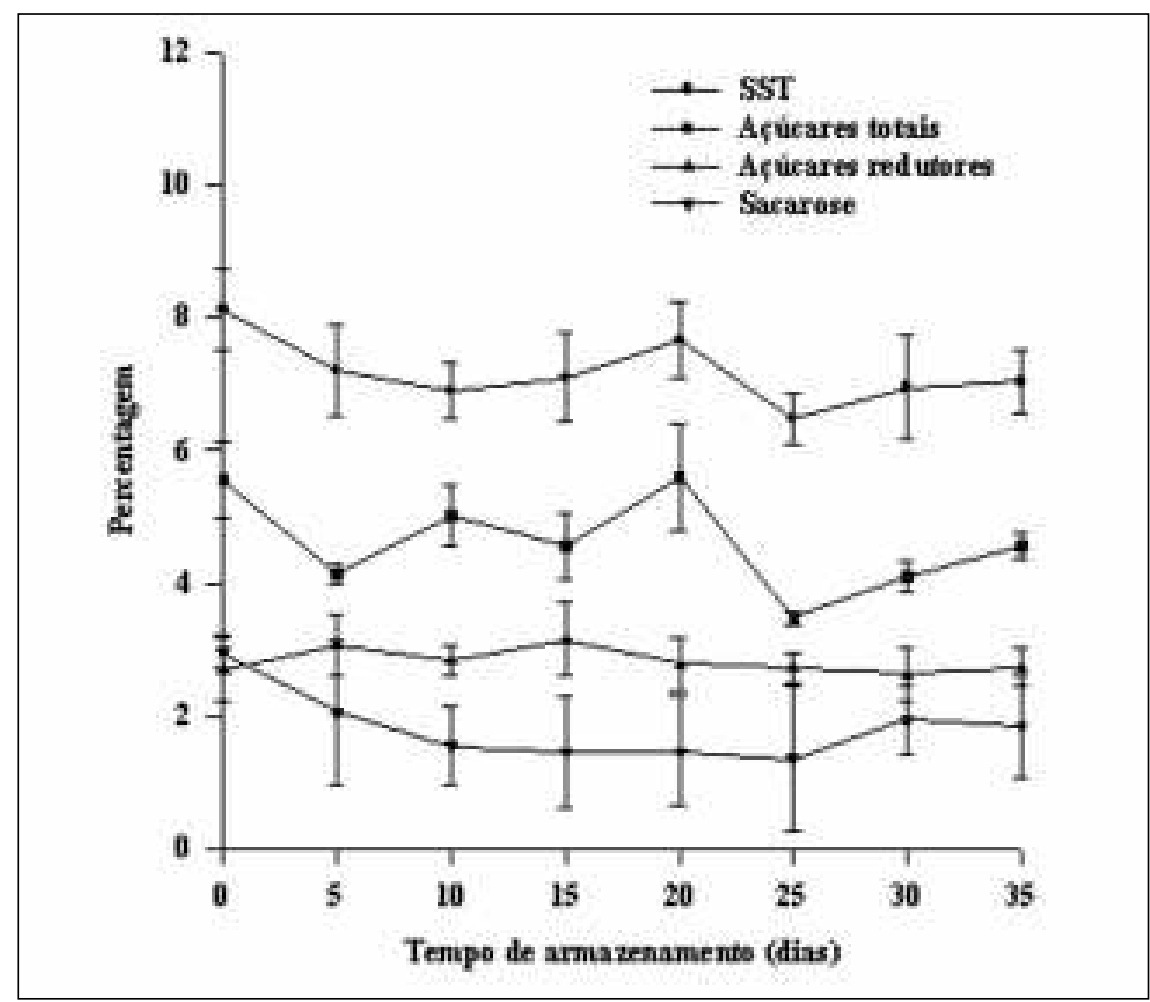

Figura 4. Clorofila total (mg/100 g de casca fresca) de melão tipo Galia, híbrido Nun 1380, armazenado durante 35 dias sob temperatura de $7^{\circ} \mathrm{C} \pm 1^{\circ} \mathrm{C}$ e umidade relativa de $88 \% \pm 3 \%$. UFLA, Lavras-MG, 1996.

armazenamento, o que é um sério problema de aceitação pelo consumidor. A perda de clorofila tem sido atribuída à ruptura dos cloroplastos e/ou à atividade de clorofilases. Diferentes hipóteses postulam que as clorofilases podem intervir tanto na síntese quanto na degradação da clorofila, apesar da função sintética ser mais comumente associada à enzima in vivo e à função catabólica in vitro (Minguez-Mosquera \& GallardoGuerrero, 1996). Outras enzimas envolvidas na degradação de clorofila são a clorofila oxidase, $\mathrm{Mg}$-dequelatase e a dioxigenase, aparentemente responsáveis pela clivagem oxigenolítica do anel porfirina. Conseqüentemente, a degradação de clorofila pode estar associada com sistemas enzimáticos oxidativos e a clorofilase pode intervir apenas no estágio inicial do processo. (Kays, 1991).

\section{LITERATURA CITADA}

AHARONI, Y.; BARKAI-GOLAN, R.; TAMKIN-GORODEISKI, N.; COPEL, A.; DAVIDSON, H. Prolonging the storage life of 'galia' melons for export (in Hebrew). Reporter Department. of Fruit and Vegetable Storage, Agr. Res. Organization, Bet-Dagan: The volcani Center, 1990, $14 \mathrm{p}$.
ARTÉS, F.; ESCRICHE, A.J.; MARTINEZ, J.A.; MARIN, J.G. Quality factors in four varieties of melons (Cucumis melo, L.). Journal of Food Quality, Westport, v. 16, n. 2, p. 91 100, 1993.

AYCWARD, F.; HAISMAN, D.R. Oxidation systems in fruits and vegetables - their relation to the quality of preserved products. Advances in Food Research, v. 17, p. 1 - 61, 1969.

BLEINROTH, E.W. Determinação do ponto de colheita. In: Netto, A.G. Melão para exportação: procedimentos de colheita e pós-colheita. Brasília, MAARA/FRUPEX, 1994. 37 p. (Série Publicações técnicas FRUPEX; 6).

BLUMENKRANTZ, N.; ASBOE-HANSEN, G. New method for quantitative determination of uronic acids. Analitical Biochemistry, v. 54, p. 484 - 489, 1973.

BRADY, C.J.; YOUNG, R.E. Fruit ripening. Annual Review of Plant Physiology, v. 38, p. $155-178,1987$.

BRUINSMA, J. The quantitative analysis of chlorophylls A and B in plant extracts. Photochemistry and Photobiology, v. 2, p. 241 - 249, 1963.

EDWARDS, M.; BLENNERHASSETT, R. Evaluation of wax to extend the postharvest storage life of honeydew melons (Cucumis melo L. var. inodorus Naud.). Australian Journal of Experimental Agriculturae, v. 34, p. 427 - 429, 1994.

ENGEL, V.L; POGGIANI, F. Estudo da concentração de clorofila nas folhas e seu espectro de absorção de luz em função do sombreamento em mudas de quatro espécies florestais. Revista Brasileira de Fisiologia Vegetal, Londrina, v. 3, n. 1, p. 39 - 45, 1991. 
EVENSEN, K.B. Effects of maturity at harvest, storage temperature and cultivar on muskmelon quality. HortScience, v. 18, n. 6, p. 907 - 908, 1983.

HAWKER, J.S. Changes in the activities of enzymes concerned with sugar metabolism during the development of grape berries. Phytochemistry, Elmsford, v. 8, p. 9 - 17, 1969.

JANDEL SCIENTIFIC. User's Manual. Califórnia: Jandel Scientific, 1991. 280 p.

KADER, A.A. Standardization and inspection of fresh fruits and vegetables. In: KADER, A.A Postharvest Technology of Horticultural Crops. California: University of California 1992, p. $191-200$.

KAYS, J.S. Postharvest Physiology of Perishables Plant Products.New York: AVI, 1991. 543 p.

KINTNER III, P.K.\& VAN BUREN, J.P Carbohydrate interference and its correction in pectin analysis using the $\mathrm{m}$ hydroxydiphenyl method. Journal of Food Science, Chicago, v. 47, p. 756 - 764, 1982.

KNEE, M; PAULL, R.E.; ARIE, R.B.; HAWKER, J.S. Enzymes in fruits. In: FOX, P.F. Food Enzymology, New York: Ensevier Applied Science, 1991. p. 545 - 598.

KRAMER, A. Fruits and Vegetables. In: TWIGG, B.A. Quality Control for the Food Industry. Connecticut: Avi Publishing Company, 1973. V. 2, p. 157 - 227.

LESTER, G.E.; STEIN, E. Plasma membrane physicochemical changes during maturation and postaharvest storage of muskmelon fruit. Journal of the American Society for Horticultural Science, v. 118, n. 2, p. 223 227, 1993.

LESTER, G.E. Lipoxigenase activity of hipodermal- and middle- mesocarp tissues from netted muskmelon fruit during maturation and storage. Journal of the American Society for Horticultural Science, Alexandria, v. 115, p. 612 - 615, 1990.
LESTER, G.E. and BRUTON, B.D. Relatioship of netted muskmelon fruit water loss to postharvest storage life. Journal of the American Society for Horticultural Science, v. 111, n. 5, p. 727 - 731, 1986.

MANNING, K.; MAW, G.A. Distribution of acid invertase in the tomato plant. Phytochemistry, v. 14, p. 1965 - 1969, 1975.

MAPSON, L.W. Vitamins in fruits. In: Hulme, A.C. The biochemistry of fruits and their products. London: Academic Press, 1970. V. 1, cap. 13 , p. 369 - 382.

McCOLLUM, T.G.; HUBER, D.J.; CANTLIFFE, D.J. Modification of polyuronides and hemicelluloses during muskmelon fruit softening. Physiologia Plantarum, v. 76, p. 303 -309, 1989.

McCOLLUM, T.G.; HUBER, D.J.; CANTLIFFE, D.J. Soluble sugar accumulation and activity of related enzimes during muskmelon fruit development, Journal of the American Society for Horticultural Science, v. 113, n. 3, p. 399 - 403, 1988.

McCREADY, P.M.; McCOOMB, E.A. Extraction and determination of total pectin materials. Analytical Chemistry, Washington, v. 24, n. 12, p. 1586 - 1888, 1952.

MICCOLIS, V.; SALTEVEIT, M.E. Influence of storage period and temperature on the postharvest characteristics of six melon (Cucumis melo L., Inodorus Group) cultivars. Postharvest Biology and Technology, Amsterdam, v. 5, p. 211 - 219, 1995.

MILLA, A. El comercio mundial de melón. Horticultura Internacional, Tarragona, n. 9, p. 74 - 75, 1995.

MINGUEZ-MOSQUERA, M.I.; GALLARDOGUERRERO, L. Role of chlorophyllase in chlorophyll metabolism in olives cv. Gordal. Phytochemistry, v. 41, n. 3, p. 691 - 697, 1996.
NORUSIS, M.J. SPSS statistics. Illinois: SPSS Inc., 1990.

RANWALA, A.P.; SUEMATSU, C.; MASUDA, $H$. The role of b-galactosidases in the modification of cell wall componentes during muskmelon ripening. Plant Physiology, v. 100, p. 1318 - 1325, 1992.

RYALL, A.L.; LIPTON, W.J. Handling trasportations and storage of fruits and vegetables: vegetables and melons, westport: AVI, 1972, v. 1, 473 p.

SAARI, N.B.; FUJITA, S.; MIYAZOE, R.; OKUGAWA, M. Distribution of ascorbate oxidase activities in the fruits of family cucurbitaceae and some of their properties. Journal of Food Biochemistry, v. 19, n. 4, p. 321 - 327, 1995.

SOUTHGATE, D.A.T. Determination of foods carbohydrates, London: Elservier Applied Science, 1991, $232 \mathrm{p}$.

STROHECKER, R.L.; HENNING, H.M. Analisis de vitaminas: metodos comprobados. Madrid: Paz Montalvo, 1967, 428 p.

TEITEL, D.C.; BARKAI-GOLAN, R.; AHARONI, Y.; COPEL, Z.; DAVIDSON, H.. Toward a practical, postharvest heat treatment for 'Galia' melons. Scientia Horticulturae, v. 45, p. 339 - 344, 1991.

WALKER, R.R.; HAWKER, J.S. Effect of pollination on carbohydrate metabolism in young fruits Citrullus lanatus and Capsicum annuum. Phytochemistry, v. 15, p. 1881 1884, 1976.

YAMAKI, S.; ISHIKAWA, K. Roles of four sorbitol related enzymes and invertase in the seasonal alteration of sugar metabolism in apple tissue. Journal of the American Society for Horticultural Science, v. 111, n. 1, p. 134 - 137, 1986. 